\title{
DE CINE, PROFESORES Y ESCUELAS. UNA PROPUESTA MULTICULTURAL SOBRE LA EXCLUSIÓN SOCIAL
}

\author{
Xosé M. Malheiro Gutiérrez \\ Universidade da Coruña \\ xmalheiro@udc.es
}

"El cine es un instrumento de pensamiento"

Jean-Luc Godard

\begin{abstract}
RESUMEN
Desde la oralidad a la imagen en movimiento, el ser humano ha intentado dar respuesta a su necesidad innata de expresión. El cine ha canalizado esa necesidad y desde su nacimiento representa una fuente documental imprescindible para observar los cambios sociales; por eso supone una herramienta didáctica de primer orden al permitirnos analizar valores, ideas, actitudes o comportamientos en diversos ámbitos profesionales. Y en ese sentido, nos aporta información relevante sobre la problemática educativa a través de sus diferentes agentes en múltiples contextos culturales y geográficos. El trabajo que se presenta centra su atención en el relato de la exclusión social en el contexto escolar tomando como referencia diez películas de este comienzo de siglo.
\end{abstract}

Palabras clave: Cine y educación. Cine y exclusión social. Docentes y cine

\section{ABOUT CINEMA, TEACHERS AND SCHOOLS. A PROPOSAL MULTICULTURAL ON THE SOCIAL EXCLUSION}

\begin{abstract}
From orality to the image in movement, the man has tried to answer to his innate necessity of expression. Cinema has canalized that necessity and since its birth represents an essential documental source to observe the social changes. Therefore it supposes a first-rate didactic tool in enabling us to analyses values, ideas, attitudes or behaviors in different professional areas. And in that regard, it gives us relevant information about the educational problem through its different agents in multiple cultural and geographic contexts.

The work that is presented focuses its attention on the social exclusion story within the educational context taking into account ten films from the beginning of this century.
\end{abstract}

Keywords: Cinema and education. Cinema and social exclusion. Teachers and cinema.

\section{SOBRE CINEMA, PROFESSORES E ESCOLAS. UMA PROPOSTA MULTICULTURAL SOBRE A EXCLUSÃO SOCIAL}

Desde a oralidade à imagem em movimento, o homem tentou dar resposta à sua necessidade inata de expressão. O cinema tem canalizado essa necessidade e desde seu nascimento representa uma fonte documental imprescindivel para observar as mudanças sociais. Por isso é uma ferramenta didáctica de primeira ordem ao permitir-nos analisar valores, ideias, atitudes ou comportamentos em diversos âmbitos profissionais. E nesse sentido, contribui com informação relevante sobre a problemática educativa através de seus diferentes agentes em múltiplos contextos culturais e geográficos. $\mathrm{O}$ trabalho que se apresenta centra sua atenção 
no relato da exclusão social no contexto escolar tomando como referência dez filmes deste começo de século.

Palavras-chave: Cinema e educação. Cinema e exclusão social. Docentes e cinema

\section{DE CINÉMA, PROFESSEURS ET ÉCOLES. UNE PROPOSITION MULTICULTURELLE SUR L'EXCLUSION SOCIALE}

\section{RÉSUMÉ}

De l'oralité à l'image en mouvement, l'homme a tenté de répondre à leur besoin inné d'expression. Le film a canalisé ce besoin et depuis sa naissance représente une source documentaire indispensable pour observer les changements sociaux; Pourquoi est un outil d'enseignement de premier ordre pour nous permettre d'analyser les valeurs, des idées, des attitudes ou des comportements dans divers domaines professionnels. Et en ce sens, il fournit des renseignements utiles sur les questions d'éducation par le biais de ses divers agents sur plusieurs contextes géographiques et culturels. Le travail présenté met l'accent sur l'histoire de l'exclusion sociale dans le contexte scolaire en ce qui concerne les dix films depuis le début de ce siècle.

Mots-clés: Cinéma et éducation. Cinéma et exclusion sociale. Enseignants et cinéma.

\section{INTRODUCCIÓN}

Desde que el ser humano tiene conciencia, ha sentido la necesidad de expresar sus vivencias, sus experiencias o sus sentimientos, y con el tiempo ha ido incorporando nuevas técnicas a esa necesidad humana de expresarse: desde la oralidad a la escritura, pasando por el arte pictórico o la fotografía, hasta llegar a la expresión tecnológica más sofisticada: la imagen en movimiento. Por eso, el cine representa el compendio de todas las técnicas anteriores como narrador de historias, transmisor de valores o portador de conocimientos susceptibles de ser utilizados con una intención didáctica.

El cine nos permite viajar al pasado o centrarnos en hechos del presente; incluso anticiparnos al futuro. $\mathrm{Y}$ en todas sus dimensiones refleja situaciones, que de una $\mathrm{u}$ otra forma, tienen un valor social. En ese sentido, Felicidad Loscertales (2001, p.119) afirma que el cine es un "fiel reflejo de la realidad social y no solo de esa realidad sino también de sus pensamientos, sentimientos, creencias y valores". Por ello supone una fuente inagotable de argumentos y de temáticas; también de lecturas y de miradas sobre una misma problemática. En la misma línea, Martínez-Salanova (2003, p.48) indica que "el cine es fuente riquísima de información y de cultura, que permite entrar realmente en el estudio de nuestra sociedad y en el de otras realidades culturales cercanas o lejanas". A las anteriores, anotamos la reflexión de García Amilguru (2009, p.11), quien afirma que a través del cine podemos captar la 
totalidad de una situación, sintiéndonos plenamente interpelados por ella. De este modo, las narraciones se incorporan a nuestra memoria de manera más persistente y permanecen en ella por mucho más tiempo.

Sin entrar en las definiciones más técnicas sobre el denominado 'Séptimo arte', porque existe abundante literatura especializada a tal efecto y trasciende el objeto de este trabajo, queremos centrarnos en su interés como instrumento de análisis de la realidad social relacionada con el mundo de la educación y, más concretamente, con la función de la escuela y el papel del docente en contextos de exclusión.

En ese sentido, como también indica Salanova, el cine es instrumento imprescindible para analizar la existencia humana, sus valores y contravalores. Todas sus posibilidades convierten al séptimo arte en un material didáctico relevante. Por un lado, porque "la imagen, tan importante en la comunicación, es convertida por el cine en irreemplazable medio de transmisión, de estudio, de investigación, de análisis y de participación en las aulas. Algo en lo que también coinciden Ambròs y Breu (2011, p.8) al sostener que el cine en la escuela "es un factor dinamizador clave para ayudar a promover valores humanizadores, de manera transversal e interdisciplinaria, y para contribuir así a desarrollar valores y elementos de identidad personal y de pertenencia”.

Pero además, porque el cine nos aporta una mirada amplia y muy variada sobre la propia profesión docente. Dentro de la temática general del cine, el reflejo de la profesión ligada a la enseñanza en el argumento de una película es un tema clásico y recurrente, ya que como mantiene Loscertales (2016, p.39), la 'figura docente', junto a la de otros campos profesionales con una fuerte carga social como la abogacía, la medicina o la policía, "forma parte de las claves básicas del imaginario colectivo de la sociedad, y por ello está presente en todos los escenarios mediáticos que contribuyan a la socialización de la población y estimulan las conductas sociales".

El cine, en fin, en palabras de Virginia Guichot (2016, p. 693), "posee un fuerte potencial socializador en la configuración de formas de pensar, de interpretar los acontecimientos, por lo que es un elemento de primer orden a la hora de crear estereotipos acerca de las realidades que presenta" en una doble vertiente: lo "sumamente atractivo", aquello que no se puede dejar de mirar, que absorbe la atención, y lo "engañoso", lo falso y manipulador.

De ahí que, en nuestra propuesta, y sin ánimo de exhaustividad, sugerimos una serie de títulos que pueden ser representativos de la problemática apuntada en líneas anteriores: el papel de la escuela y del docente en contextos de exclusión social. Son películas relativamente

Rev. Iberoam. Patrim. Histórico-Educativo, Campinas (SP), v. 3, n. 1, p. 97-121, jan./jun. 2017 
recientes, en su mayor parte producidas en la última década, aunque algunas de ellas se refieran a hechos del pasado próximo. Al mismo tiempo, hemos tratado de que, compartiendo una misma problemática, nos acerquen a realidades cultural y geográficamente diversas.

\section{Wu Ge Xiao Hai De Xiao Zhang (Little big master, Pequeña gran maestra, Adrian Kwan,} 2015)

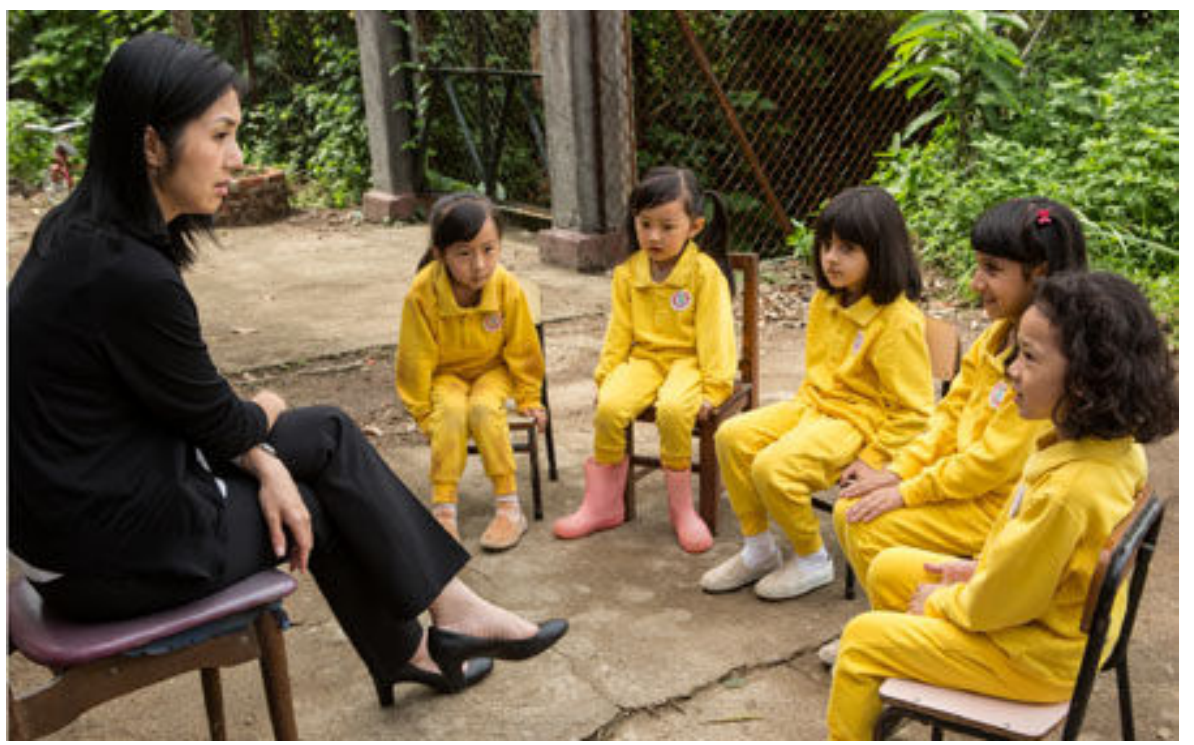

La acción se sitúa en Hong Kong, inspirada en hechos reales. Es la historia de una maestra de educación infantil, Lillian Lui, que goza de un trabajo aparentemente confortable como directora en una prestigiosa escuela privada. Pero su concepción de un determinado modelo educativo choca con algunos aspectos de la vida en el centro, como la mentalidad competitiva de algunos padres, obsesionados por los logros académicos de sus hijos párvulos, o el obsesivo interés que muestra el Consejo por los beneficios económicos del colegio. A causa del ambiente que se vive en el centro, decide renunciar a su puesto y tomarse un descanso.

Casualmente recibe la noticia de una escuela infantil condenada al cierre, a menos que alguien quiera hacerse cargo de los cinco alumnos que aún permanecen allí. ${ }^{1}$ Lui acepta la oferta hasta encontrar otra ubicación para los niños. Sus familias carecen de los recursos

\footnotetext{
${ }^{1}$ Existen elementos de conexión, también, con el caso de Monsieur Lazhar (Profesor Lazhar, 2011), que Philippe Falardeau nos sitúa en Montreal. Un supuesto maestro de origen argelino, Bachir Lazhar, se ofrece como sustituto en un colegio tras la muerte por suicidio de una profesora.
} 
necesarios para dar una salida al problema ${ }^{2}$. De este modo, y a cambio de un salario muy por debajo de su categoría, se compromete a desempeñar, a la vez, el puesto de directora, limpiadora y única profesora, de forma provisional. Cuando conoce a los niños y descubre la fragilidad del contexto en que se mueven y su estigma de pobreza, emprende una lucha en la que también implica a su marido: "Mi sueño es ser la mejor profesora para los cinco que esperan por mí, en la puerta de la escuela, cada mañana".

Con las dosis correctas de melodrama, Adrian Kwan presenta una historia profundamente emotiva, sin obviar la complejidad sociocultural del sistema escolar de Hong Kong, caracterizado por una profunda división de clases. ${ }^{3}$ Adrian Kwan utiliza la vida de la escuela para introducirnos en ese complejo sistema de desigualdad en que conviven Lillian Lui y sus alumnos Ka-ka (Fu Shun-Ying), Chu-Chu (Keira Wang), Siu-Sebo (Ho Yuen-ying) y las hermanas paquistaníes Kitty (Zaha Fathima) y Jenny (Khan Nayab).

La profesora proviene de un estrato acomodado, mientras que ellos y sus familias pertenecen a un submundo apartado y casi 'invisible' tras los destellos del emporio financiero. El contacto progresivo con su alumnado le permite conocer su entorno y las repectivas problemáticas familiares ${ }^{4}$. El padre de Siu-sebo (Richard Ng) vive de la recogida de chatarra y a su madre, originaria del continente, se le niega el derecho de residencia. Chu-chu vive con una tía (Anna Ng), que se hizo cargo de él a la muerte de sus padres en un accidente de tráfico y trabaja precariamente fregando platos en un restaurante. El padre de Ka-ka (Philip Keung) padece una discapacidad y mantiene continuas discusiones con su mujer en presencia del pequeño, atenazados por la presión de las mafias locales sobre la casa en la que viven; Kitty y Jenny tienen que lidiar con su padre, reacio a escolarizarlas en un modelo diferente a los valores de su cultura.

El apoyo de la maestra resulta fundamental para que los padres recuperen la conexión afectiva con sus hijos. Y aquí está, en cierto modo, el mensaje (nada original, por cierto), de la

\footnotetext{
${ }^{2}$ En otra latitud y cultura diferentes, se hace presente la vinculación entre problemática familiar y situación escolar de los alumnos: padres en paro, desbordados por situaciones cotidianas de pobreza, enfermedad, marginación desamparo en la solución de sus problemas: Ça commence aujourd'hui (Hoy empieza todo, Bertrand Tavernier, 1999).

${ }_{3}^{3} 1,3$ millones de personas, de los 7,3 millones que residen en Hong Kong, vive en situación de pobreza, lo que supone casi la quinta parte de la población de un país que el FMI sitúa en el puesto 25 de entre los más ricos del mundo por PIB nominal, con 36.218\$ per cápita, inmediatamente detrás de Gran Bretaña. Sin embargo, la mitad de su población reside en vivienda pública y de protección social, por no poder acceder al mercado inmobiliario (SUBIRACHS, 2014, p.233).

${ }^{4}$ Existe algún paralelismo con Beyond the Blackboard (Detrás de la pizarra, Jeff Bleckner, 2011), basada en una historia real. En este caso, la del primer trabajo como maestra que asume Stacey Bess (Emily VanCamp), una chica de 24 años que se enfrenta a la dura realidad de un refugio para familias sin techo donde, 'la escuela', es un salón desvencijado, sin nombre y sin más recursos que unos pocos pupitres, un tablero y un almuerzo proporcionado por el gobierno escolar. Aquí Stacey Bess también encontrará en su marido un incondicional apoyo para afrontar sus problemas.
} 
película: el rendimiento académico depende tanto de las aptitudes de los estudiantes para el aprendizaje como de los condicionantes que tenga el contexto en el que se desarrollan. La película también retrata a Lui y a Dong como dos personas voluntariosas y desprendidas cuyos horizontes se proyectan más allá de su cómoda existencia burguesa.

Desde una mentalidad oriental, Pequeña gran maestra parece indicarnos que no hay soluciones fáciles contra el malestar social. Las personas no tiene capacidad para curar muchos de los males de la sociedad que les toca vivir, simplemente se puede lograr un alivio a través de una aceptación resignada...

\section{Katmandú, un espejo en el Cielo (Icíar Bollaín, España, 2011)}

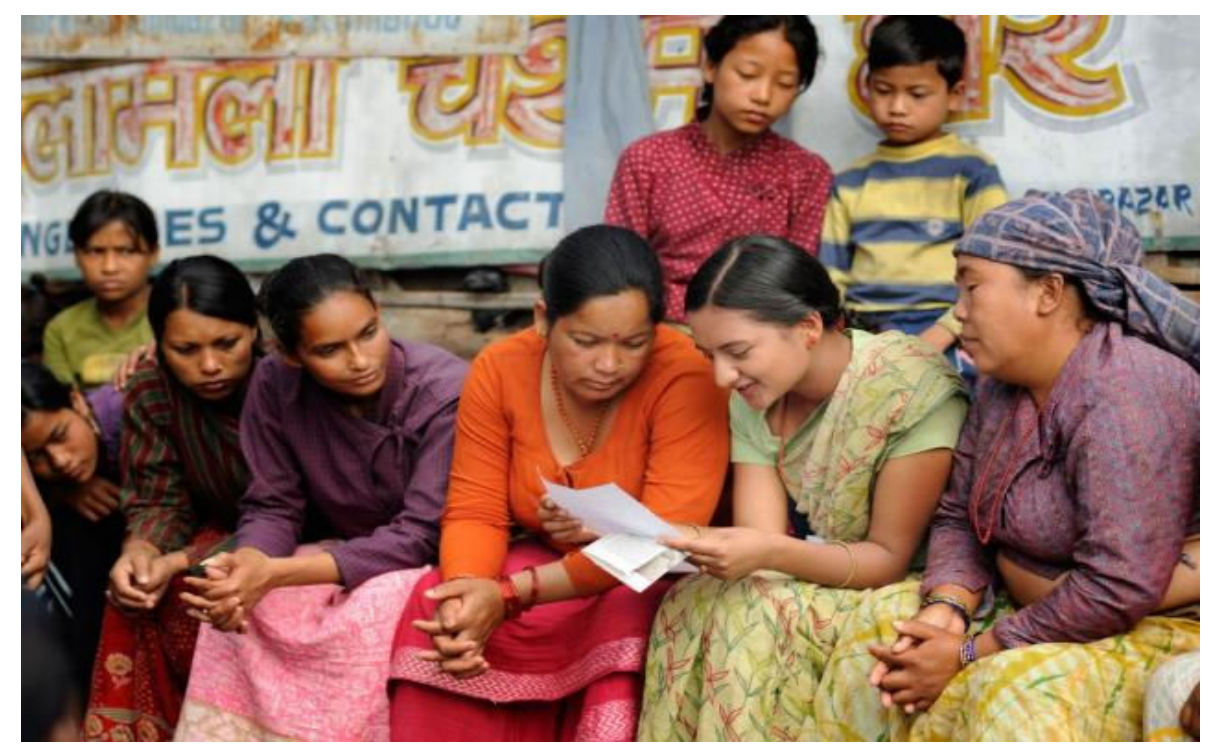

He aquí otra historia de implicación personal: la experiencia que una joven maestra catalana, Victòria Subirana, llevó a cabo a comienzos de los años noventa en la capital del $\mathrm{Nepal}^{5}$. Laia (Verónica Echegui), se traslada a Katmandú en 1988 con su curiosidad de viajera, cierta documentacion sobre la realidad del país y algunos deseos de romper con la monotonía de una vida cómoda. A través de un conocimiento idílico previo y mucha simpatía occidental hacia la vertiente mística de la cultura nepalí, Laia emprende su viaje con 29 años. Pero sufre el impacto de una realidad terrible al primer contacto, que ya nunca la abandonaría:

\footnotetext{
${ }^{5}$ Las vivencias de esta maestra quedarían plasmadas en su novela Una Maestra en Katmandú. Madrid, Aguilar, 2012.
} 
el de los niños en la calle, con las barrigas hinchadas por la desnutrición hurgando entre la basura y "el olor intenso y agridulce de los pobres". 6

Es así cómo la joven profesora descubre a los "Dalits", la casta más baja y marginada del Nepal. Los llamados "intocables", sometidos al repudio del resto de la sociedad. Y con ese impacto toma la decisión de quedarse para colaborar solidariamente creando una escuela. ${ }^{7} \mathrm{Y}$ lo acaba consiguiendo, no sin afrontar múltiples dificultades, incluso poniendo en riesgo su vida.

En Katmandú, un espejo en el Cielo, Icíar Bollaín nos ofrece una mirada contundente y por momentos documental, de la realidad nepalí, que va engranando con cuidado efecto: el sistema de castas, la situación de la mujer, la corrupción de las instituciones públicas, los problemas de la educación relacionados con la extrema pobreza... Son experiencias vividas por Victòria Subirana que, por su crudeza, desearíamos que fuesen solo ficción. Laia se acerca a las viviendas miserables de los Dalits, entre las callejas pestilentes de Sinamangal, el barrio más deprimido de Katmandú, reclutando niños para su proyecto; lucha contra el rapto de adolescentes con destino a los burdeles de Bombay; trata de paliar el trabajo forzado de los niños ayudando a las madres en su manutención, colabora con las mujeres en su lucha sin desmayo por salir de la miseria, se enfrenta a una burocracia corrupta e indolente, denuncia el mercadeo de puestos escolares o trata de impedir los castigos físicos en su escuela.

De este modo, a través de Katmandú, un espejo en el Cielo, Iciar Bollain nos presenta el proyecto que Victoria Subirana creó a partir de aquella primera experiencia: una estructura educativa solidaria, que acaba tomando forma en 1990 a través de la Fundación EduQual, gracias al apoyo de varias administraciones e instituciones españolas y que forman diferentes proyectos basados en la pedagogía como herramienta transformadora, con un cierto aroma freireano: "Para actuar en contra de la 'falsa caridad', es necesario dotar a los más necesitados de aquellas herramientas que habrán de permitirles alcanzar el nivel de dignidad al que tienen derecho todos los seres humanos sin ningún tipo de discriminación".

\footnotetext{
${ }^{6}$ Nepal es un país lastrado por la desigualdad a causa del convulso panorama político de las últimas décadas y su corrupción sistémica. Más de un $80 \%$ de los nepalíes son analfabetos; de ellos, una parte importante es población asentada, procedente del Tibet. Esta región sufrió la invasión y anexión china en 1950, y una parte considerable de su población se vio forzada al exilio, principalmente a India, Nepal y Bután. Mucha de ella condenada, desde entonces, a vivir en condiciones de extrema pobreza y marginación.

${ }^{7}$ Este argumento tiene algunos elementos de conexión con Laskar Pelangi (The Rainbow Troops, Riri Riza, Indonesia, 2008), que a su vez se inspira en la novela autobiográfica The Rainbow Troops, de Andrea Hirata, publicado en España con el título La tropas del arco iris por Ediciones Temas de Hoy, 2013. También existen conexiones con The Corn Is Green (El trigo está verde, George Cukor, 1979), en la que Miss Moffat (Katharine Hepburn), una joven inglesa que se va a vivir a un pueblo minero de Gales, se queda impactada cuando comprueba que en las minas también trabajan niños. Se plantea entonces la necesidad de hacer algo por ellos y decide escolarizarlos. Es, a su vez, una nueva adaptación de la obra de Emlyn Williams, que ya en 1945 conoció una versión protagonizada por Bette Davis bajo la dirección de Irving Rapper.
} 


\section{El corral y el viento. Miguel Hilari, Bolivia, 2014}

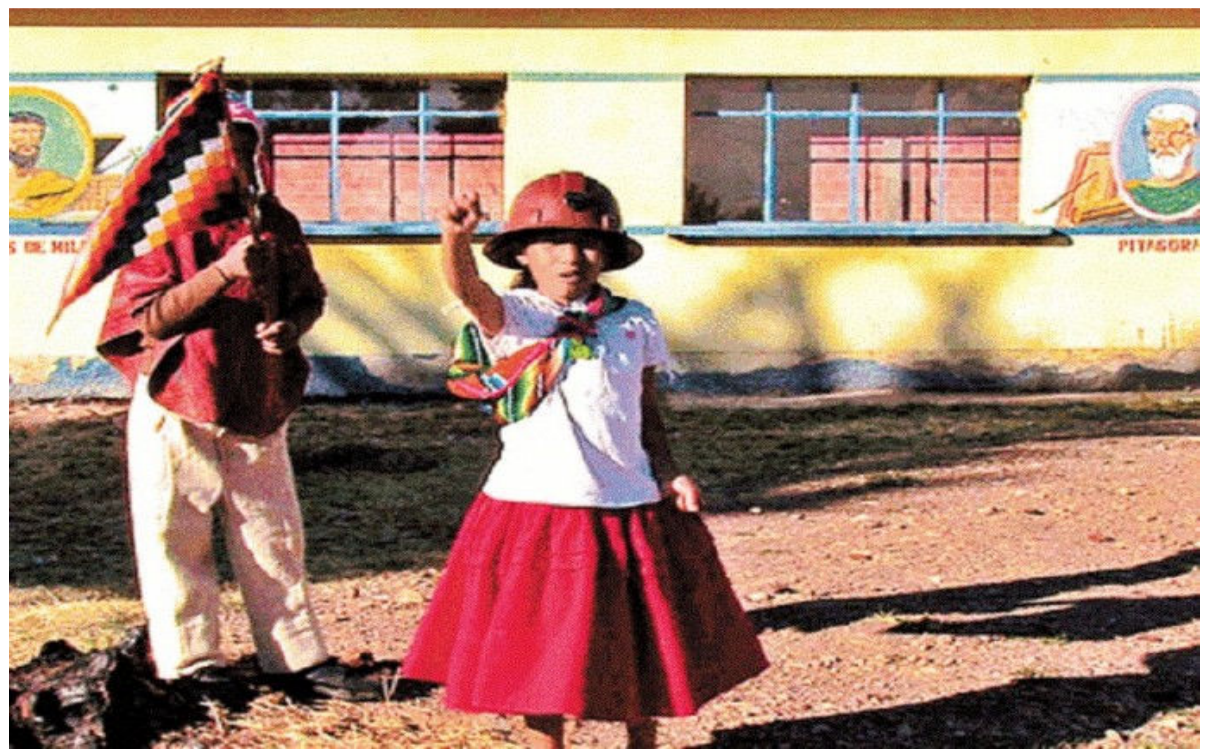

El corral y el viento centra su atención en el conflicto entre tradición y progreso. Miguel Hilari ahonda en las raíces rurales de los pueblos indígenas en su confrontación con la modernidad vinculada a la cultura urbana. Para ello toma como referencia la lucha identitaria del pueblo aymara frente al proceso colonizador.

Santiago de Okola, el pueblo bañado por las aguas del lago Titicaca donde se desarrolla este documental (nótese la imposición del topónimo), es el lugar de nacimiento del abuelo de Hilari. El realizador evoca las dificultades de los aymara para su alfabetización, sometidos a una especie de cerco cultural sobre el aprendizaje de la lectura, la escritura o el idioma español, con el fin de apartarles del conocimiento sobre la legislación y el funcionamiento del Estado. Impedir la educación era una forma más de violencia simbólica contra su derecho a reivindicar la autodeterminación. Años después, Paulo Freire hablaría del poder de la palabra a través de la alfabetización para hacer a los humildes dueños de sus destinos...

Ante la falta de respuesta oficial a la demanda alfabetizadora, fueron naciendo escuelitas rurales clandestinas, regentadas por maestros nativos, como símbolo de la resistencia aymara frente al sistema feudal del altiplano. Escuelas sometidas a una fuerte represión por parte de la oligarquía terrateniente, bajo el amparo de las autoridades:

Mi abuelo, en esa época, fue al pueblo mas cercano donde vivían vecinos o pequeños terratenientes de una clase social superior a los campesinos, y cuando habló con las autoridades del pueblo para pedir una escuela, lo encerraron en un corral de burros y le dijeron: "burro eres, burro te vas a quedar". 
El corral y el viento invita a la reflexión, además, sobre el concepto de cultura y sus conflictos en el complejo contexto latinoamericano, susceptible de ser analizado en varios planos. Por un lado, el proceso de aculturación de los pueblos indígenas, sometidos a la presión que ejerce la idealización de la cultura urbana como modelo de progreso: una de las razones por las que Hernán, el adolescente que protagoniza los primeros minutos de la cinta, quiere irse a la ciudad es porque en ella "hay luz". Considera, además, duro el trabajo en el campo, por eso de mayor le gustaría marcharse para trabajar de albañil (¿?). Estas interferencias, que sin duda producen una brecha creciente en la comunicación intergeneracional, quedan simbólicamente reflejadas en la perturbación que produce el paso de un avión sobre el cielo limpio de Santiago: la invasión tecnológica del espacio aéreo es también analogía de la que se produce en el espacio cultural e ideológico.

Por otro lado, la fuerte migración a las ciudades va alterando el sistema de valores de la sociedad aymara. Irremediablemente, se asumen nuevas formas de convivencia y de relación con el mundo y la distancia que se establece respecto a la cultura ancestral, genera crisis de identidad, especialmente entre los jóvenes.

Por último, la relación de la escuela y el medio rural. El documental se detiene en los efectos de la educación oficial como instrumento 'normalizador' frente a la resistencia indígena por conservar sus creencias y costumbres. De este modo el currículum oficial, por ejemplo, silencia la historia aymara en favor de la europea 'clásica'. Pedro Hilari se detiene en mostrar la carga ideológica de la izquierda indigenista en las declamaciones que realiza una pequeña estudiante de segundo grado de primaria al pie de su escuela rural. $\mathrm{Y}$, aunque es admirable la resistencia que mantiene la maestra frente al sistema educativo oficial, inculcando a su alumnado el orgullo aymara, es también manifiesta la contradicción de su propia debilidad: porque los poemas independentistas que de forma solemne recitan sus alumnos, lo hacen en el idioma de los conquistadores, aquéllos que les han relegado a la asfixia de la altitud geográfica y al aislamiento administrativo.

A propósito de la anterior contradicción, El corral y el viento nos deja una pregunta en el aire en la que la escuela juega un papel muy importante: ¿aferrarse a las tradiciones en aras de una identidad ancestral o adaptarse a un presente asimilando nuevos elementos culturales y otros valores más próximos a los colonizadores? 
Buda az sharm foru rikht (Buddha Collapsed out of Shame, Buda explotó por vergüenza, Hana Makhmalbaf, Irán, 2007)

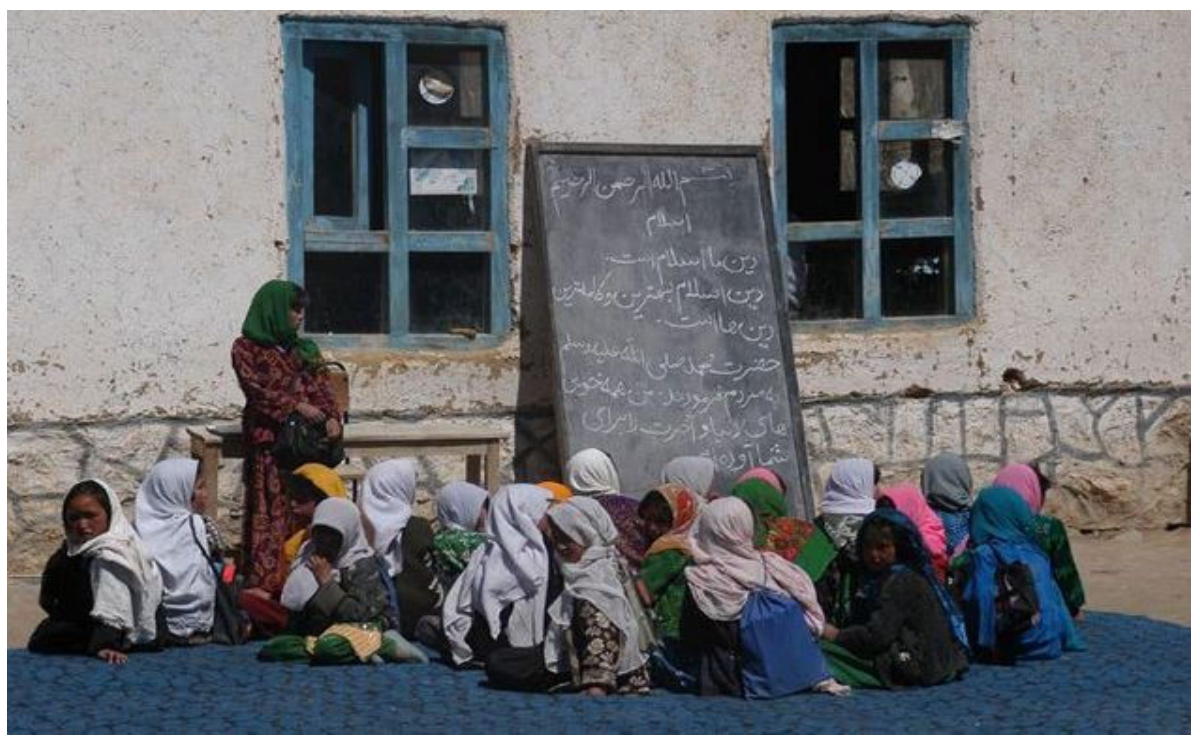

Hana Makhmalbaf pertenece a una familia de cineastas iraníes comprometidos con los problemas sociales y políticos de una de las regiones más conflictivas del planeta ${ }^{8}$. En Buda explotó por vergüenza, aborda la historia de Batkay (Nikbakht Noruz), una niña que quiere ir a la escuela pero carece de un lápiz y un cuaderno, material imprescindible para que pueda ser admitida. Está rodada en Bayimán, la población afgana que saltó a los medios de comunicación en 2001 por la voladura de dos gigantescas estatuas de Buda a manos del régimen talibán.

La historia de Batkay es una metáfora sobre la vida de las mujeres en situación de pobreza, que se agudiza por efecto de la guerra y la ortodoxia fundamentalista. Hana Makhmalbaf plantea varios asuntos que invitan a la reflexión. En primer lugar, el lugar de la mujer bajo el régimen talibán ("solo eres un bicho insignificante que no puede ir a la escuela"), donde la destrucción de valores como la igualdad, la libertad o la justicia impiden su desarrollo natural como persona. Impacta una escena en la que, ante las dificultades para conseguir el lápiz necesario, Batkay decide utilizar un pintalabios de su madre, lo que provoca que unos críos, que juegan a ser talibanes, decidan apresarla y simulen lapidarla.

\footnotetext{
${ }^{8}$ Hana Makhmalbaf (Buda explotó por vergüenza, 2007) es hermana de Samira Makhmalbaf (La pizarra, 2000 y A las cinco de la tarde, 2003); hijas, a su vez, de Mohsen Makhmalbaf, a quien películas como Gabbeh (1995), El silencio (1997), Dastan hay Jazeereh (Tales of as Island, 2000), Kandahar (2001) y The Gardener (2012) han convertido en uno de los cineastas más importantes de Irán. Su madre, Marziyeh Meshkini, guionista de algunas de sus películas, es la realizadora de Stray Dogs (2004).
} 
Aquí aparece la segunda cuestión: los modelos sociales de convivencia que adopta la infancia, en los que se 'normaliza' la violencia por efecto de la guerra. Makhmalbaf recrea su espacio lúdico y muestra cómo el juego infantil refleja el escenario bélico cotidiano, pervirtiendo su naturaleza y aceptando la violencia como único modelo de convivencia ${ }^{9}$. Y así educa una generación a la siguiente, perpetuando un sistema que dificulta la ruptura y el cambio. Un cambio que tiene su punto de partida en el derecho universal a la educación para hacer efectivo el desarrollo natural e igualitario.

Éste es el tercer problema: la precariedad de las condiciones en las que se desarrolla la alfabetización y escolarización de la infancia. Niños que aprenden básicos rudimentos a la intemperie, entre escombros, en locales que algún día fueron aulas, a manos de maestros toscos e insensibles, soportando duros castigos físicos entre rutinas memorísticas.

Por último, la ausencia de libertad impuesta por el régimen talibán. Buda explotó por vergüenza es la historia de una niña empeñada en ir a la escuela. Para conseguirlo tiene que sortear muchas dificultades en un inagotable ejercicio de tenacidad. Y llama la atención la ausencia de los padres en su esfuerzo por llegar a la escuela. Batkay simboliza, en fin, esa infancia abandonada a su suerte, condenada a la pobreza crónica, a la desigualdad y falta de oportunidades, víctima de injustas imposiciones culturales, sociales y religiosas. Batkay lucha por encontrar un lugar en la escuela, que no deja de ser el camino necesario para encontrar su lugar en el mundo.

\footnotetext{
${ }^{9}$ No podemos olvidar Lakposhtha hâm parvaz mikonand (Turtles Can Fly, Las tortugas también vuelan, Bahman Ghobadi, 2004) una historia terrible contada por un realizador muy próximo a la familia Makhmalbaf (Ghobadi interpreta al maestro Reeboir en La Pizarra). Un escenario de extrema violencia en el que un grupo de niños, absolutamente solos e indefensos, tratan de sobrevivir localizando y desactivando minas antipersona en las inmediaciones de un campo de refugiados kurdos, por cierto, sin escuelas ni maestros. La historia se sitúa en los días previos a la intervención militar norteamericana contra el régimen de Sadam Hussein. Es un ejemplo descarnado de las horribles secuelas emocionales que las guerras pueden dejar en las mentes infantiles.
} 


\section{Dancing arabs (Mis hijos), Eran Riklis, Israel, 2014}

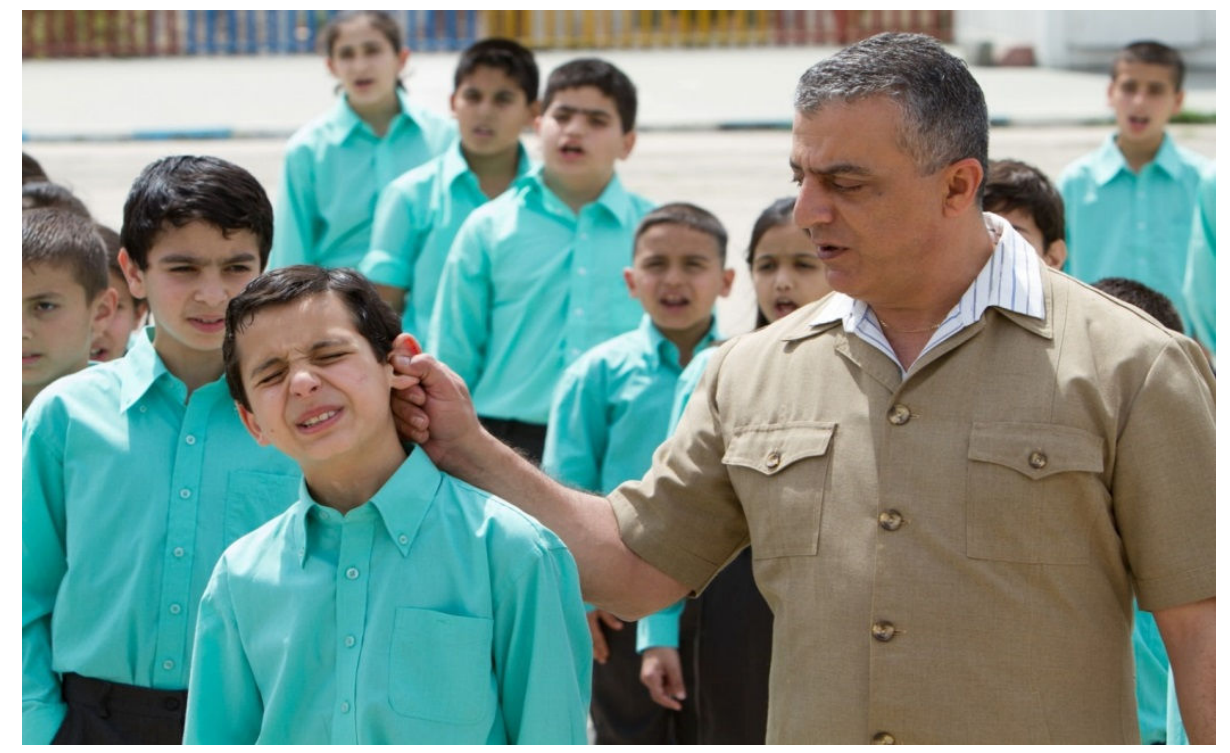

Dancing arabs (Mis hijos) de Eran Riklis, ${ }^{10}$ toma el título de la expresión "bailando en dos bodas", que lleva al dilema de una población que quiere vivir tanto con su identidad árabe como con su nacionalidad israelí, y a los innumerables conflictos derivados de esa doble (des)lealtad.

Dancing arabs trata las tensiones de Oriente Próximo a través de la historia de Eyad (Tawfeek Barhom), un tímido, introvertido pero brillante alumno palestino que crece en una ciudad árabe dentro de Israel a comienzos de los 80 . Gracias a su esfuerzo y a la presión que ejerce su padre Tira (Ali Suleiman) por entender que la educación es la única vía de progreso, lo envía a la más prestigiosa escuela secundaria israelí en Jerusalén. En ese contexto debe superar múltiples dificultades relacionadas con el 'curriculum oculto' del colegio y la enorme presión que ejerce ese medio ${ }^{11}$. En este conflicto de identidad, se ve obligado, por ejemplo, a fingir que acepta la historia en su versión pro-semita contada en el colegio, para evitar que le marginen ("Los árabes rechazaron el plan de división e intentaron boicotear el Estado judío. Cuando se aceptó el Plan, en 1947, los árabes iniciaron una serie de atentados contra la comunidad judía y eso fue el detonante de la guerra de la independencia”).

El idioma en el que aprende, así como el currículo que estudia, pertenecen a una cultura y a una visión de la realidad diferentes a la suya, y Eyad nunca puede olvidar que es

\footnotetext{
${ }^{10}$ Adaptación de una novela autobiográfica de Sayed Kashua. Arabes danzantes. Salamanca, Tropismos, 2006.

${ }^{11}$ Una problemática inversa es la que se trata en School Ties (Colegio privado, 1992). En 1950, David Green, un adolescente judío de clase media, recibe una beca en una elitista escuela preuniversitaria de Nueva Inglaterra (USA). A cambio debe mantener en secreto su procedencia.
} 
un extraño en ese mundo. Además de en el colegio, otros escollos se le plantean en el terreno del amor, de la amistad, del trabajo o de las convenciones sociales que dificultan su integración en este ambiente ajeno a su cultura y determinan la oportunidad de seguir estudiando.

Afortunadamente no todo son dificultades: a través de un programa de voluntariado, entra en contacto con Jonathan (Michael Moshonov), un muchacho israelí que padece distrofia muscular y con su madre Edna (Yael Abecassis). Esta relación de amistad muestra la humanidad del joven palestino y le lleva a convertirse, más adelante, en parte de esa familia. Hay aquí una secuencia conmovedora, cuando Eyad, en su labor comunitaria como asistente de Jonathan, carga en brazos el cuerpo paralizado hasta su cama, donde lo acuesta con sumo cuidado. Este acto de ternura fraternal, que choca con las ráfagas constantes de muerte y violencia que asoman en los televisores a lo largo de la película, es también una metáfora terrible sobre la utópica relación entre ambas culturas.

Dancing arabs (Mis hijos) plantea el conflicto de un joven palestino que opta por sacrificar su identidad en aras de la aceptación social en un contexto de opresión. Es el dilema de quien nada entre dos aguas y se convierte, al final, en un extraño, acabando por no pertenecer a ninguna de ellas. Esta situación podría trasladarse de modo general a cualquier contexto en otra latitud. Se trata, en fin, de la respuesta existencial a la opresión cuando un individuo, un pueblo, una cultura, una lengua... sucumbe, en su debilidad, perdiendo ahí una parte importante de si mismo.

\section{Examen d'Etat, Dieudo Hamadi, República del Congo, 2014}

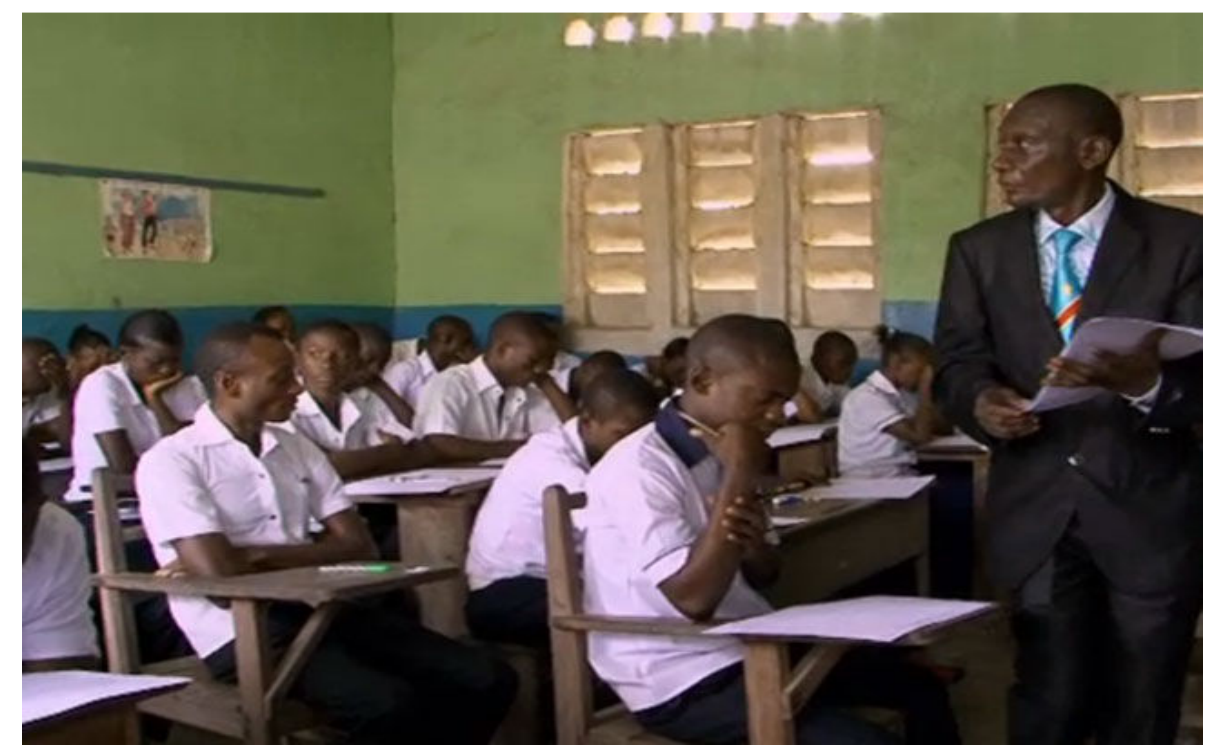


La República del Congo (RC) es el segundo país más pobre del mundo. Datos de Unicef confirman que el $70 \%$ de la población congoleña vive por debajo del umbral de pobreza. Su gobierno ha firmado diferentes tratados por los que, en teoría, se garantiza el derecho a una escolarización gratuita y obligatoria ${ }^{12}$, pero más de la mitad de la población adulta nunca ha ido a la escuela o sólo ha completado la enseñanza primaria, lo que sitúa el porcentaje de analfabetos en el 43\%. En este país centroafricano viven 35 millones de jóvenes con edad inferior a los 18 años; de entre ellos, el 97\% no tiene acceso a la educación preescolar y la tasa de abandono se acerca al 45\% antes de acabar la educación primaria.

La legislación de la RC dispone que, al menos ese nivel sea gratuito, pero la escasez de recursos financieros y la falta de instalaciones para atender las necesidades de su población infantil explica las cifras precedentes. De este modo, se admite de forma 'alegal' que el propio gobierno, las colectividades locales o las instituciones escolares exijan a los padres una cuota 'voluntaria' para equilibrar su déficit, complementar el sueldo de profesores o satisfacer el derecho a exámenes u otros gastos.

Esta práctica dificulta el derecho a la educación y abre una brecha en la igualdad de oportunidades favoreciendo solo a aquéllos que pueden sufragar los costes. Además, exige a los padres sacrificios que corresponden el Estado, estimula la corrupción y convierte a los maestros en una especie de mercaderes de su propio conocimiento, pervirtiendo su función como difusores públicos de un saber que, por ser patrimonio común, no debe someterse a un valor especulativo.

Una situación compleja que Dieudo Hamadi, un joven realizador congoleño aborda en Examen d'Etat. Este documental ofrece un retrato conmovedor de las dificultades que padece un grupo de estudiantes de secundaria del Athénée Royal para someterse a una especie de reválida, necesaria para obtener el certificado de estudios secundarios. Como es de suponer, para miles de jóvenes congoleños acceder al Diploma Nacional es un asunto vital, por la importancia que supone para su futuro un título universitario en un país con tal porcentaje de población analfabeta. ${ }^{13}$

La historia sucede en Kisangani. El Athénée Royal es un centro educativo público de glorioso pasado en el Zaire colonial de los años 50, pero con un presente marcado por la

\footnotetext{
${ }^{12}$ Pacto Internacional relativo a los derechos económicos, sociales y culturales (arts. 13 y 14); Convención relativa a los Derechos de la Infancia (arts. 28 y 29); Convención sobre la eliminación de todas las formas de discriminación hacia las mujeres (art. 10) o la Carta Africana de los Derechos Humanos y de los Pueblos (art. 17) (http://www.jrs.net/assets/regions/ior/media/files/kisanganiedues.pdf).

${ }^{13}$ Existe un producción británica basada en una historia real The First Grader (Justin Chadwick, 2010). Recoge la ilusión de un anciano keniata analfaneto de 84 años, que desea ir a la escuela aunque ello suponga compartir clase con niños de seis años.
} 
decadencia y el desgobierno ${ }^{14}$. En el Athénée royal, los exámenes de Estado en algunas especialidades apenas llegan al 50\% de aprobados y es común la práctica de corruptelas por parte del profesorado. En tal estado de abandono, los alumnos que no han podido satisfacer a los profesores la cuota correspondiente, son excluidos del sistema oficial y deben preparar el examen por su cuenta.

La cámara de Dieudo Hamadi acompaña a los jóvenes por las caóticas calles de Kisangani mientras sortean mil dificultades con el propósito de realizar las pruebas y lograr el aprobado. Desde la preparación de sahumerios en los que intervienen "brujos" locales hasta la auto-organización en "maquis", una especie de residencias donde los estudiantes se hospedan para reunirse y preparar la reválida de forma comunal.

Examen d'Etat hace un retrato incisivo de la sociedad congoleña actual. La decadencia del Athénée Royal es un reflejo de la descomposición del sistema social de la RC. A través de ese complejo microcosmos, nos acerca a una sociedad que trata de olvidar la guerra que ha asolado el ex-Zaire entre 1996 y 2002. Un país lastrado por un pasado colonial, sucedido de periodos de guerra civil y dictaduras criminales, que ahogan un presente de dificultades y trazan un futuro de incertezas para ese $70 \%$ de población que Unicef sitúa por debajo del umbral de pobreza.

Además de una voz de alarma sobre el avanzado estado de abandono en que se encuentra el sistema educativo de la RC y sus consecuencias, Examen d'État es el grito de resistencia de una juventud que no acepta una realidad impuesta, llena de arbitariedades, y lucha por alcanzar sus legítimos derechos.

${ }^{14}$ El Athénée Royal ha sido rehabilitado en 2015 centroafricano.( http://www.stanleyville.be/athenee.html\#) 


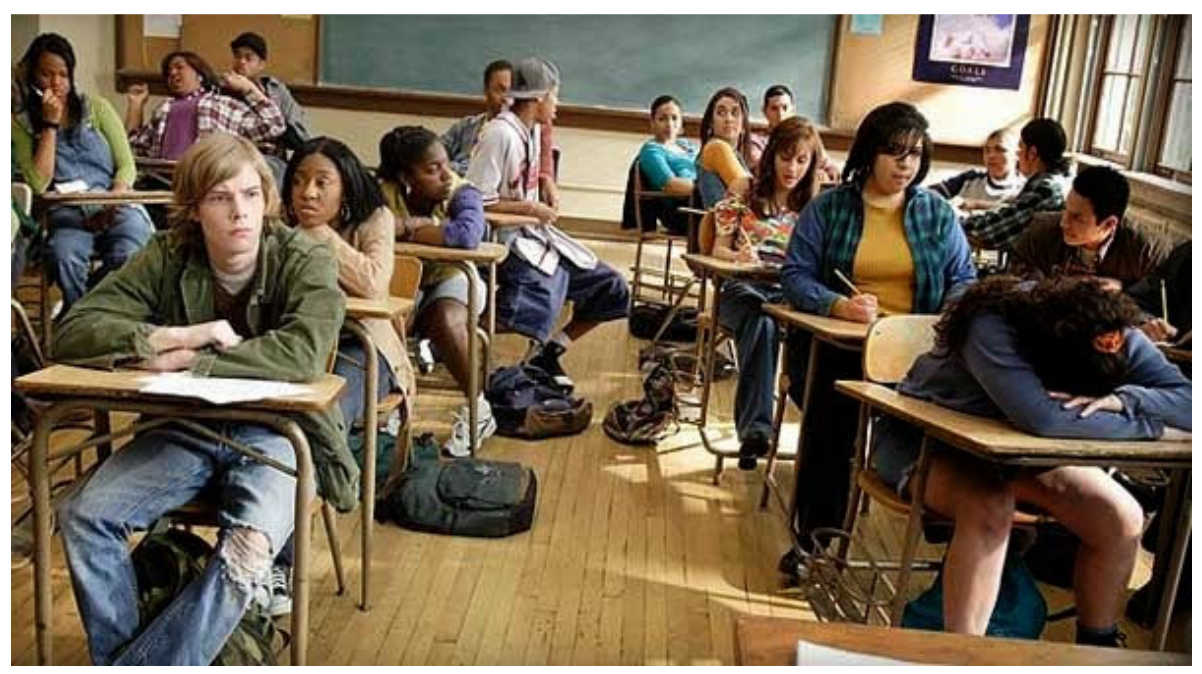

Ese grito de rebeldía es el que también se escucha entre el alumnado del Woodrow Wilson Classical High School. Freedom Writers (Diarios de la calle), del director Richard LaGravenese $^{15}$, narra la historia real de Erin Gruwell (Hilary Swank) y la experiencia que llevó a cabo en el Instituto Wilson Classical de Long Beach (California) tras los disturbios de Los Ángeles en 1992 por conflictos interraciales ${ }^{16}$.

Diarios de la calle vuelve sobre un tema que ya ha tratado el cine en diversos trabajos, alguno citado en estas páginas, donde el docente entregado a su profesión, voluntarioso e innovador, llega a una comunidad conflictiva y se enfrenta a un alumnado escéptico y desmotivado, víctima de un entorno de miseria, violencia e injusticia ${ }^{17}$.

Esta joven consigue una plaza de profesora de Literatura, a donde llega con un aspecto convencional de clase media, una gran dosis de idealismo y mucha ilusión para hacerse cargo

\footnotetext{
${ }^{15}$ Basada en la novela de Erin Gruwell El diario de los escritores de la libertad. Barcelona, Editorial Elipsis, 2007.

${ }^{16}$ Anteriormente, otros directores ya se habían ocupado de esta problemática en las escuelas: The Blackboard Jungle (Semilla de maldad, Richard Brooks, 1955), The learning tree, (El árbol de la sabiduría, Gordons Park, 1969), Halls of Anger (Odio en las aulas, Paul Bogart, 1970), The bus is coming (Wendell Franklin, 1971), Cooley High (Michael Schultz , 1975), Stand and deliver (Lecciones inolvidables, Ramón Menéndez, 1987), School daze (Aulas turbulentas, Spike Lee, 1988), Los chicos del barrio (Boyz $N$ the hood, John Singleton, 1991), Higher learning (Semillas de rencor, John Singleton, 1995).

${ }^{17}$ Es el caso del profesor Mark Thakeray, que encarna Sidney Poitier en la clásica To Sir, with Love (Rebelión en las aulas, James Clavell, 1967), la profesora que interpreta Michelle Pfeiffer en Dangerous Minds (Mentes peligrosas, John N. Smith, 1995); Julia Roberts en Mona Lisa Smile (La sonrisa de la Mona Lisa, Mike Newell, 2003); Gérard Jugnot en Les Chortistes (Los chicos del coro, Christophe Barratier, 2004), Ted Danson en Knights of the South Bronx (Los caballeros del sur del Bronx, Allen Hughes, 2005); Matthew Perry en The Ron Clark Story (Unidos para triunfar, Randa Haines, 2005); Hilary Swank en Freedom Writers (Diarios de la calle, Richard LaGravenese, 2007); François Bégaudeau en Entre les murs (La clase, Laurent Cantet, 2008); Jürgen Vogel en Die Welle (La ola, Dennis Gansel, 2008), Adrien Brody en The Teacher (El profesor, Tony Kaye, 2011) o Ariane Ascaride en Les héritiers (La profesora de Historia, Marie-Castille Mention-Schaar, 2014) por citar algunas de las últimas y quizá las más conocidas.
} 
de un grupo multiétnico de adolescentes de diversas procedencias, algunos recién salidos del reformatorio, acostumbrados al estigma de la marginación en sus respectivos entornos. Con un entusiasmo encomiable, Erin se afana por ganarse la confianza y el respeto de sus alumnos, y se encuentra el rechazo permanente a sus propuestas de participación y diálogo ${ }^{18}$. A la actitud del alumnado debe sumarse el clasismo que destila el propio 'curriculum oculto' del Centro y la indiferencia de algunos compañeros, abandonados a su suerte en medio de las dificultades de la profesión:

\begin{abstract}
Éste era un instituto de primer nivel, y mire cuando han llegado en que lo han convertido. Es decir, ¿tiene sentido que los chicos que quieren tener una educación deban sufrir porque su instituto se transforme en un reformatorio? ¿Por qué chicos que no quieren estar aquí, y no deberían estar aquí, se ven obligados a estar aquí por los "genios" que dirigen la Junta de Educación? La integración es una mentira, pero los profesores no podemos decirlo porque nos echarían por racistas. ${ }^{19}$
\end{abstract}

Un incidente de tinte xenófobo entre alumnos mientras trabajan La Odisea la lleva a interrumpir la clase para cambiar el discurso y hablarles de los horrores del nazismo y las consecuencias del Holocausto jugando con una analogía de símbolos. Con mucha intuición, varía el plan de trabajo y cambia la obra clásica por El Diario de Anna Frank. Sin embargo, la falta de apoyo de la Dirección para llevar a cabo su método no la desanima y sigue adelante, aportando sus propios recursos. Como parte del proyecto, les entrega unos cuadernos que deben utilizar como diarios, para expresar regularmente lo que deseen: "Podéis escribir de lo que queráis. El pasado, el presente, el futuro... Podéis escribir como en un diario, o podéis escribir canciones, poemas, cosas buenas, cosas malas... lo que sea. Pero tenéis que escribir todos los días. Tened un boli a mano para cuando os venga la inspiración. ¡Y no llevará nota!" 20 . La rápida implicación de los chavales consigue que la actividad transforme su sentido estrictamente académico en una terapia liberadora de la negatividad que acumulan y se convierta en un instrumento de afirmación vital frente a su caótico entorno:

Mi agente de la condicional no entiende que los institutos son como la ciudad, y la ciudad es como una cárcel, con todos divididos en distintas secciones dependiendo de la tribu. Está la "Mini Camboya", el "Guetto", el "Reino de las Barbies" y nosotros, el "Sur de la frontera" o "Mini Tijuana". Así son las cosas y todo el mundo

\footnotetext{
${ }^{18}$ En algún aspecto nos recuerda también a Up the Down Staircase (Contra corriente, Robert Mulligan, 1967) y a la joven profesora Sylvia Barret (Sandy Dennis) en la escuela secundaria de Calvin Coolidge.

19 "Carceleros, no somos otra cosa. Se iguala por debajo y se sacrifica a los mejores. Así todo el mundo está contento. Casi toda mi clase se muere de aburrimiento todo el día. Parecen condenados a galeras. ¿Quién decidió que la escuela debía ser obligatoria? Cuatro años de liceo técnico para acabar en el paro". Así se expresa Lajoie (Josiane Balasko), otra profesora 'quemada', en Le maître d'école (El maestro de escuela, Claude Berri, 1981).

${ }^{20}$ Existen muchos elementos en común con P.R.O.F.S. (La venganza de los profes, Patrick Schulmann, 1985), en la que un grupo de jóvenes profesores utiliza métodos poco ortodoxos para atraer la atención de sus alumnos y elevar su espíritu crítico.
} 
lo sabe. Pero en seguida hay algún payaso que intenta pisarte en el instituto exigiendo un respeto que no se ha ganado. Funciona así...

No pasa desapercibida una secuencia que recoge el diálogo, mientras cenan, entre Erin, su marido y el padre de ella, un acomodado burgués, en otro tiempo activista social por los Derechos Humanos:

Padre: Bueno, qué tal el trabajo?

Erin: Papá...

Padre: Le preguntaba a tu marido.

Marido: Va bien, por ahora. Es una buena empresa. Y yo dirijo el departamento de informática.

Padre: ¿No eras arquitecto??

Erin: Y lo es... pero se ha tomado un descanso.

Marido: Y me pagan bastante.

Padre: ¿Y cuánto ganas tú? ¿Veitisiete mil dólares brutos?? (dirigiéndose a Erin).

Erin: Si lo sabes ¿por qué me preguntas?

Marido: Bueno, ¿qué vais a tomar? (trata de desviar la tensión de la conversación)

Padre: Con tu cerebro podrías dirigir una gran compañía, en cambio tengo que preocuparme porque eres profesora en esa cárcel.

Freedom Writers es el reconocimiento a un tipo de profesorado entusiasta, abnegado, ilusionado, incombustible ${ }^{21}$, que se enfrenta a la soledad de la clase, a la indiferencia de la profesión, a la arbitariedad del sistema, y quizá lo más grave de todo: a la falta de gratitud por una parte importante de la sociedad. Y a pesar de todo, logra éxitos para su alumnado.

\section{Non è mai troppo tardi (El maestro, Giacomo Campiotti, Italia, 2014)}

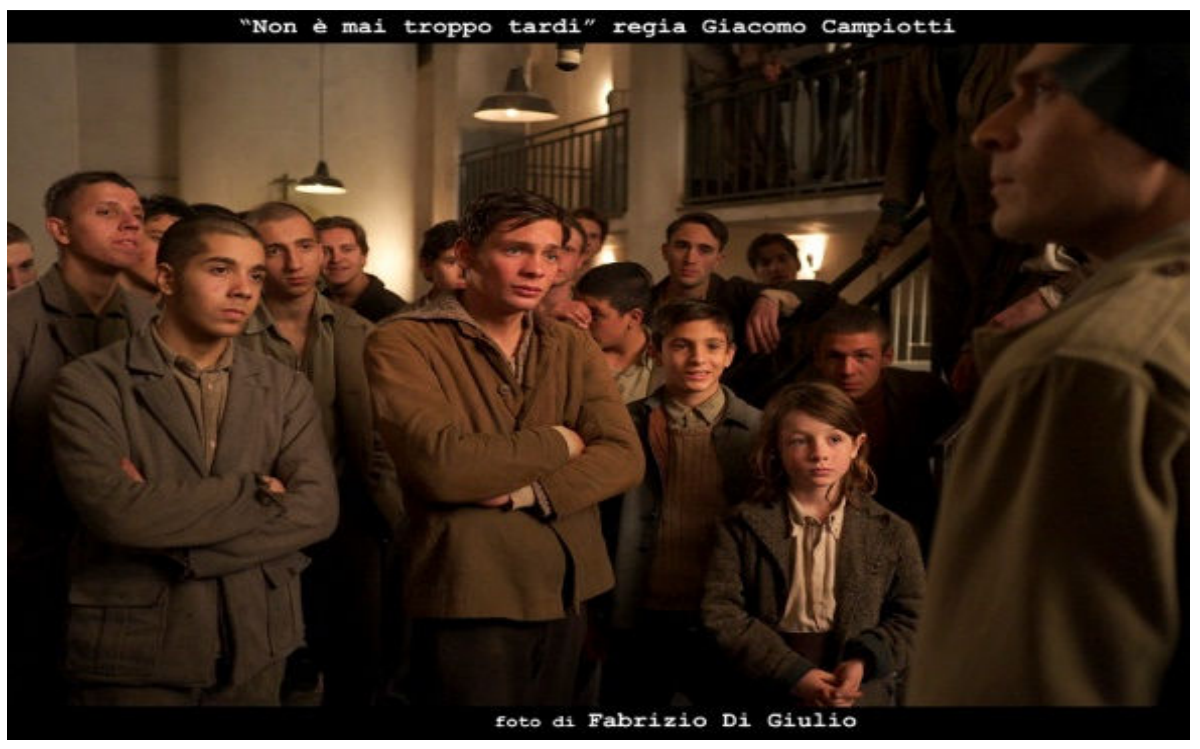

${ }^{21}$ Otros trabajos anteriores, además de los ya citados, nos muestran este tipo de docente: To Sir, with Love (Rebelión en las aulas, James Clavell, 1967), High School High (Aprende como puedas, Hart Bochner, 1996) o Class of 1984 (Curso del 84, Mark L. Lester, 1982), por citar algún ejemplo, aunque también entrarían otros títulos a los que se hace referencia a lo largo del trabajo. 
En Non è mai troppo tardi (Nunca es demasiado tarde, traducción del original) de Giacomo Campiotti (2014), hay una coincidencia con Los diarios de la calle en el método que utiliza el docente para resolver una situación de conflicto y provocar un cambio positivo a través de una tarea motivante.

El título alude a un programa educativo emitido entre 1960 y 1968 por la RAI, que hizo célebre a Alberto Manzi, un profesor muy reconocido en Italia. Algunos años atrás, en 1946, recién regresado de la guerra, Manzi (Claudio Santamaria) acepta un trabajo como maestro en la cárcel de menores Aristide Gabelli, de Roma ${ }^{22}$. Dentro de los muros del reformatorio, trata de introducir métodos pedagógicos contra el criterio de la Dirección. Esto genera tensiones adicionales a su ya complicada tarea, porque los propios internos, sometidos a constantes castigos y vejaciones, tampoco ven en ello ninguna utilidad.

\footnotetext{
Director: Manzi, ¿como le va?

Manzi: Bien

Director: A juzgar por su cara, cualquiera lo diría...

Manzi: Pero ¿de qué lado está? Usted sabe bien que me siento un inútil. No tengo libros, cuadernos, bolígrafos. No pueden leer, no pueden escribir...

Director: Si se hiciera acompañar por los guardias, al menos sería escuchado.

Manzi: No quiero a los guardias, porque de lo contrario, los niños fingirían que me escuchan. Así, por lo menos son honestos.

Director: Pero, ¿qué está pensando, Manzi? ¿Realmente cree que podemos hacer algo por ellos? ¿Eh? Ellos no saben qué les espera cuando salgan de aquí: padres que se emborrachan, hermanos que están en la cárcel, las familias que no tienen nada para comer... ¿Para qué enseñarles La Divina Comedia a estos chicos si en un par de años van a estar aquí de nuevo?
}

Contraviniendo las normas, consigue introducir algunos lápices y papel, material indispensable para crear un estímulo, y a partir de ahí lograr que escriban sencillos textos en los que vuelcan sus verdaderas historias, sus temores, ilusiones, esperanzas... Una pequeña revolución que culminó en La Tradotta, cabecera de una rudimentaria revista elaborada a partir de los textos que fueron escribiendo, como expresión de la pedagogía terapéutica que Alberto Manzi consiguió implantar, al fin, con el visto bueno de las autoridades. Y que fue, además, el primer periódico que se imprimió en un correccional italiano.

El maestro simboliza la férrea confianza del educador en la condición humana como principio básico de su oficio: no existe barrera que no se pueda derribar, ni riesgo que no se deba asumir en la tarea de enseñar. Basta con aplicar el principio de la corresponsabilidad y

\footnotetext{
${ }^{22} \mathrm{El}$ tema de los reformatorios ha inspirado muchos films. En Mery per sempre (Rejas de cristal, Marco Terzi, 1989) y al contrario que Alberto Manzi, Marco Risi elige trabajar como docente en un reformatorio donde aprende que algunas actitudes de los internos no son sino un grito de auxilio y ansia de libertad. Otros films sobre reformatorios, empezando por un clásico: Les quatre cents coups (Los cuatrocientos golpes, François Truffaut, 1959), The Loneliness of the Long Distance Runner (La soledad del corredor de fondo, Tony Richardson, 1962), Scum (Escoria, Alan Clarke, 1979), Sleepers (Barry Levinson, 1996), Gridiron Gang (La vida en juego, Phil Joanou, 2006).
}

Rev. Iberoam. Patrim. Histórico-Educativo, Campinas (SP), v. 3, n. 1, p. 97-121, jan./jun. 2017 
una gran dosis de confianza. Sirva como ejemplo la secuencia en la que, gracias a los resultados precedentes, consigue sacar a los chavales del correccional para disfrutar de un día de excursión. Manzi los sitúa en un arriesgado dilema: les ofrece la libertad por ese día, al tiempo que les transfiere la responsabilidad de no huir, pese a la oportunidad de poder hacerlo. Saben que sería malograr el éxito que entre todos, con tanto esfuerzo, han ido alcanzando. Y el fin de quien tanto les ha apoyado. Al final, la jornada se celebra en medio de una gran excitación, pero a la hora convenida, todos acuden al lugar indicado para regresar en bus, de nuevo, al correccional.

\section{El profesor de violín, Sergio Machado, Brasil, 2015}

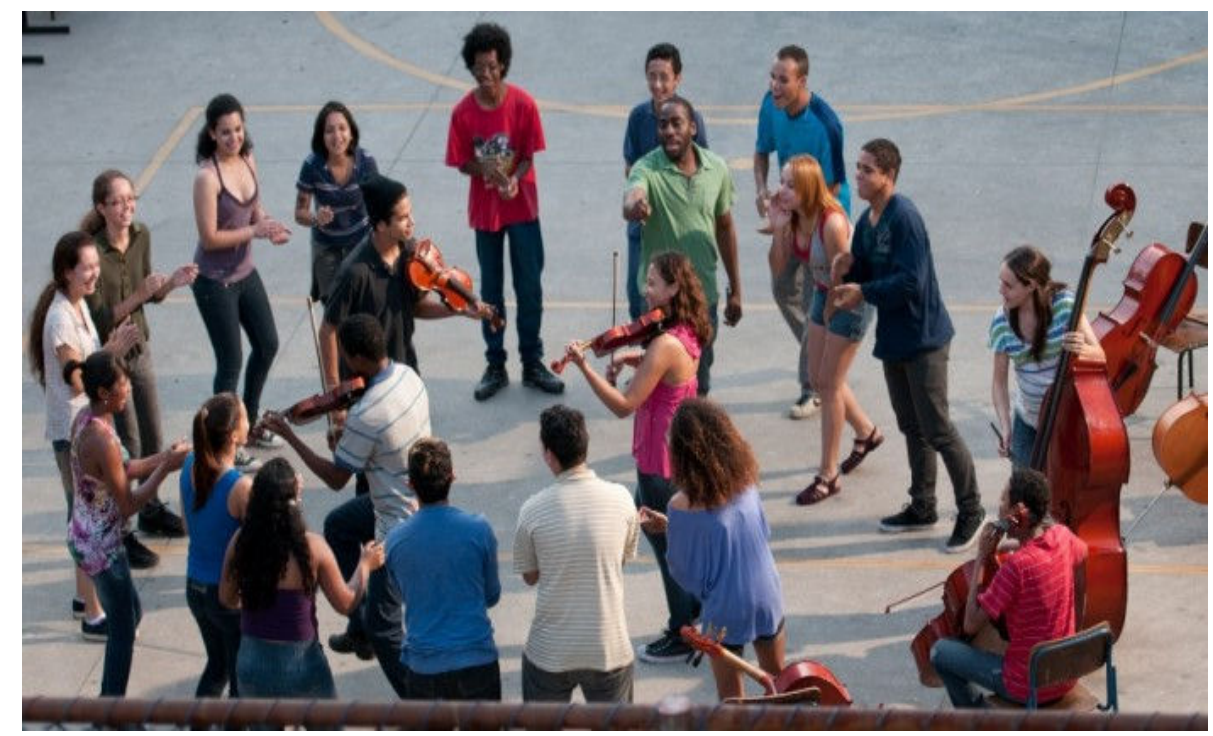

En El profesor de violín, o Tudo que aprendemos juntos, Sérgio Machado recrea la historia real de un músico de orquesta que inicia su carrera como docente en Heliópolis. El personaje de la historia es el maestro Silvio Baccarelli, un joven profesor de violín que encarna Lázaro Ramos (Laerte), protagonista central de la película.

El Instituto Baccarelli nace a principios de los años noventa del siglo pasado en Heliópolis (San Paulo, Brasil). Esta institución atiende en la actualidad a un millar de niños y jóvenes en situación vulnerable a través de programas formativos al servicio de la prevención, que les proporcionan desarrollo personal y la oportunidad de iniciar un camino en el mundo de la música. La Sinfônica Heliópolis, cuyos inicios están en la orquesta del Instituto Bacarelli, viaja dando conciertos por todo el mundo, acompaña a maestros como Ennio Morricone y tiene como padrinos a músicos de la talla de Zubin Mehta. 
Machado narra los inicios de Laerte en esta escuela de música, a donde llega después de un intento frustrado para ingresar en la Orquesta Sinfónica del Estado de São Paulo, una de las más prestigosas de América latina. Este contratiempo en sus expectativas profesionales le obliga a replantearse la vida y aceptar un puesto de profesor de música en una de las favelas más populosas y conflictivas del país.

Pese a ese escenario, que Sergio Machado logra recrear con eficacia a través del trabajo de actores que, salvo en el caso de Lázaro Ramos, son habitantes de la propia favela, pero imprimen realismo al ambiente violento del aula, a las escenas de la convivencia familiar, a la vida de la calle en la favela, en el modo de divertirse... Pese a ello, Laertes consigue transformar con éxito una situación, a priori complicada, porque es capaz de llegar a la raíz del problema, vinculado a la carencia de afecto familiar y a las escasas expectativas de futuro.

El profesor de violín describe la transformación que se produce en la vida de unos jóvenes rebeldes cuando se ponen en marcha energías liberadoras, gracias a una intervención pedagógica basada en la humanidad, la autoridad y la sensibilidad a través de la música. Y es, a la vez, la transformación personal de Laerte, un profesor de clase media que llega al centro arrastrando su propia frustración y los prejuicios iniciales de clase hacia Heliópolis, un foco de desarraigo y conflictividad ${ }^{23}$. Pero acaba cautivado por la fuerza que mueve a aquellos jóvenes cuando se les toca el afecto. Una transformación en su actitud que también se traslada a la propia forma de organizar el espacio: la rigidez autoritaria del aula cuadriculada va cediendo a la disposición circular, más flexible y participativa, a medida que cambian actitudes y se propicia el encuentro.

$\mathrm{Y}$ el personaje crece al tiempo que se enfrenta a diversos conflictos, ya sean internos del aula o en los morros de la favela, donde Sérgio Machado crea un universo dramático apoyado por un fondo musical que concilia con acierto el grito rapero de Sabotage o Rappin' Hood, con el virtuosismo clásico de la propia Sinfônica.

Tudo que aprendemos juntos es un canto al esfuerzo de superación, apoyado en una historia real. El de la vida de Laerte, desde sus comienzos con el violín; es, también, el estímulo de su familia, que supo acompañarlo y alimentar su talento intuyendo el logro de una vida mejor. Y es además, un reflejo de la historia personal de Sérgio Machado, que consiguió cumplir el sueño de convertirse en realizador a pesar de sus orígenes modestos, gracias a su

\footnotetext{
${ }^{23}$ Esta actitud inicial está también presente en Mr. Holland's opus (Profesor Holland, 1995), en la que Glen Holland, músico de profesión, acepta un trabajo a regañadientes y sólo de forma provisional, pues su verdadera vocación es la de compositor, pero acaba realizando un magnífico trabajo como docente.
} 
propio tesón y al esfuerzo de sus padres. Y aunque la película pone el foco en la exclusión social y en la violencia como problemas aparentemente irresolubles de la sociedad brasileña actual, deja abierta una puerta a la esperanza, por el poder de transformación que se produce en un medio cuando se aplican estrategias pedagógicas adecuadas. ${ }^{24}$

\section{Les choristes (Los chicos del coro, Christophe Barratier, Francia, 2004)}

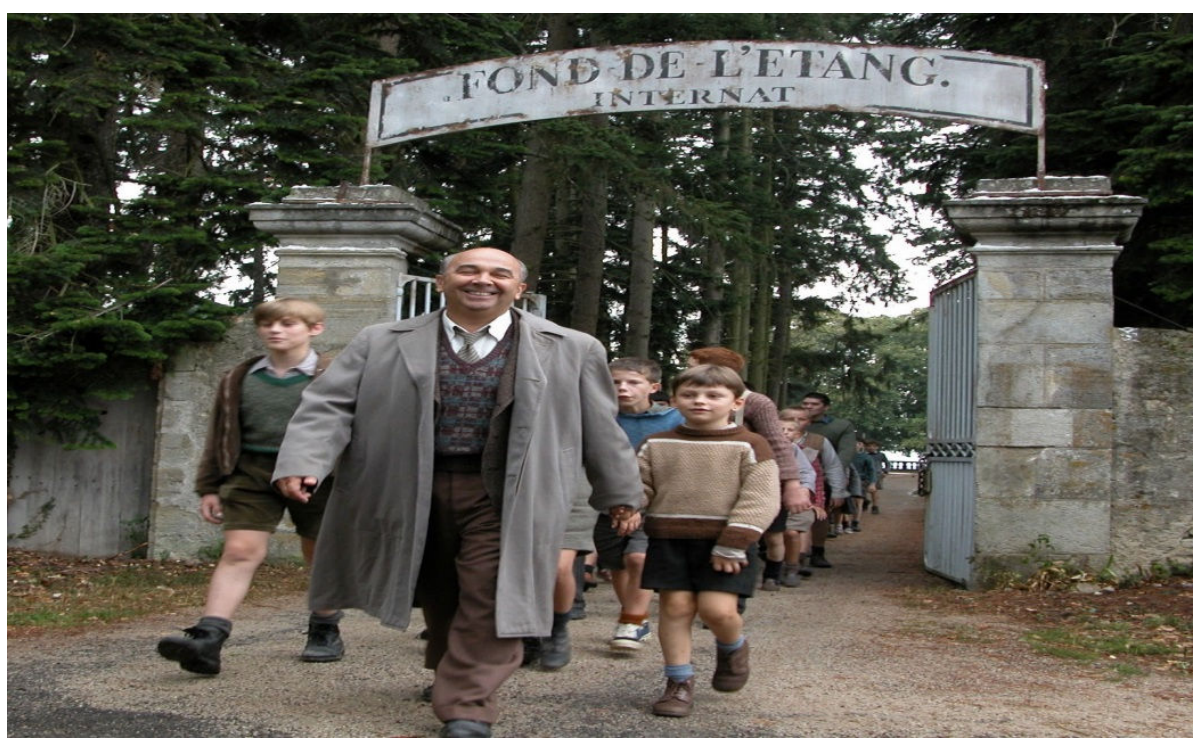

Siguiendo en la línea de reflexión sobre la verdadera naturaleza del éxito y del fracaso, Christophe Barratier quiere mostrarnos en Les Choristes, el efecto de dos modelos pedagógicos opuestos. De una parte, disciplina, represión y castigo; de otra, sensibilidad, afecto, reconocimiento y promoción de las propias potencialidades. Dos modelos que expresan dos dimensiones del concepto frommiano de autoridad: 'tener' o 'ser'.

Como en otras obras, señala los efectos positivos del arte, en este caso la música en entornos conflictivos, para promover el desarrollo personal a través de una tarea grupal ${ }^{25}$. Para este trabajo, Christophe Barratier se inspiró en La jaula de los ruiseñores (La cage aux rossignols, Jean Dréville, 1945), que trata también la historia de Clement Mathieu (Noël Noël), un profesor que llega a un internado para alumnos problemáticos y consigue implicarlos en la organización de un coro infantil.

\footnotetext{
${ }^{24}$ Sobre esta temática debemos citar también Maroa (2005) de Solveig Hoogesteijn.

${ }^{25}$ En El club de los poetas muertos (Peter Weir, 1989) y The Kindergarten Teacher (La profesora de parvulario, Nadav Lapid, 2014) ocurría con la poesía; en Cinema Paradiso (Giuseppe Tornatore, 1988) con el cine; en Music of the Heart (Música del corazón, Wes Craven, 1999) con el violín; en Billy Elliot (Quiero bailar, Stephen Daldry, 2000) era la danza.
} 
La acción se desarrolla en el año 1949 en Francia. Clément Matthieu (Gérard Jugnot), un profesor de música sin trabajo, acepta el puesto de "guarda, enfermero, encargado de almacén y cristalero" en Fond de l'Étang (Fondo del Estanque), un internado para chavales de extracción humilde, cada uno arrastrando su propia historia de abandono, de pobreza o de marginalidad $^{26}$. Como el pequeño Pepinot (Maxence Perrin), que espera cada sábado, tras la verja, la llegada de su padre, porque ignora que murió en la guerra; o la del protagonista, Pierre Moranghe (Jean-Baptiste Maunier), expulsado de la escuela pública por sus innumerables fugas, cuya madre, Violette, madre soltera, no le puede mantener aunque se preocupa por él y lo visita periódicamente. O la de Pascal Mondain (Grégori Gatignol), expulsado del centro por un robo que no cometió y predestinado a acabar como delincuente, merced a los diagnósticos de la psiquiatría infantil oficial de los años cincuenta y de los prejuicios del director Rachin (François Berléand): "no debe preocuparse, Mathieu. Si hoy no es culpable lo habría sido mañana. Esa gente no tiene remedio, no lo tiene".

El centro se rige por un sistema disciplinario represivo, según el principio de "acciónreacción" impuesto por el propio Rachin, cuya violencia incrementa el estigma de los muchachos y refuerza su posición de constante rebeldía. Hay, además, en su actitud despectiva y clasista una inmensa frustración: "Nunca tuve vocación de educador. Y no me diga que usted soñaba con enterrarse en este culo del mundo. ¡Tendrá ambiciones, como yo!’”.

Pero la llegada de Mathieu introduce nuevos elementos en la dinámica del internado. $\mathrm{Su}$ forma de actuar, combinando humanidad en el trato, firmeza en las decisiones, afecto en la relación y una cierta complicidad frente a la incompetente autoridad de Rachin, acabará por ganarse la confianza de los chavales. Mathieu descubre que la música atrae poderosamente su interés y aprovecha ese resorte para organizar un coro que, además de suavizar la dureza de las relaciones impuesta por la disciplina cuartelaria del director, introduce en los muchachos una nueva percepción del mundo y de sus relaciones con los demás.

A través de esta película, en cierto modo autobiográfica, Christophe Barratier llama la atención sobre el poder de la música, y del arte en general, para transformar el destino de personas que, atendiendo a sus orígenes y en términos de darwinismo social, estarían condenadas al fracaso.

\footnotetext{
${ }^{26}$ El tema de los internados ha dado abundante material al cine. Entre las más recientes, la irlandesa The Magdalene Sisters (Las Hermanas de la Magdalena, Peter Mullan, 2002) sobre maltrato a mujeres; en la también irlandesa Song for a Raggy Boy (Los niños de San Judas, Aisling Walsh, 2003) el maltrato infantil; en la española La mala educación (Pedro Almodóvar, 2004) educación religiosa y homosexualidad; en la surcoreana Do-ga-ni (Silenced, Silenciado, Hwang Dong-hyuk, 2011) abusos sexuales; en la ucraniana Plemya (The Tribe, La Tribu, Miroslav Slaboshpitsky, 2014) delincuencia en las bandas juveniles.
} 
Sin que lleguen a ocupar un espacio central en el guión, en Los chicos del coro subyacen también otros temas. Uno de ellos es el de la falsa filantropía ligada a la beneficencia con la que, en otros tiempos, la aristocracia reafirmaba su posición de poder y privilegio. $\mathrm{O}$ el de la paternidad y la maternidad ${ }^{27}$, que aquí aparece marcado en dos situaciones: la figura de la madre de Pierre Moranghe y el del propio Mathieu, con la adopción final de Pepinot.

Los chicos del coro narra, en fin, una historia de éxito colectivo, protagonizada por un grupo de fracasados, lo que nos lleva a reflexionar sobre el auténtico significado de ambos conceptos.

\section{CONCLUSIÓN}

La propuesta que presentamos refleja distintos contextos culturales que comparten muchos de sus elementos. De ese modo, todas las películas muestran entornos en los que destaca una forma de violencia. Puede ser directa, por ejemplo, por efecto de la guerra o sus secuelas en el contexto europeo de la posguerra mundial (Los chicos del coro o El maestro). Puede ser por una guerra reciente (Buda explotó por vergüenza o Examen d'Ėtat); o por una guerra latente, como en el contexto palestino de Mis hijos.

En otros casos, la violencia está presente a través del ambiente urbano de las favelas (El profesor de violín) o de los barrios multirraciales norteamericanos (Diarios de la calle). Otras veces, en fin, toma formas más sutiles, a causa del propio sistema, como en Pequeña gran maestra, El corral y el viento o Katmandú.

Pero todos los escenarios comparten una situación de violencia estructural generada por la pobreza, la exclusión y la falta de oportunidades. Violencia que deja secuelas emocionales en la infancia y la juventud, y que la escuela trata de neutralizar, o al menos de paliar, con su mejor herramienta. Por ello, pese a todo, siempre emerge la figura del educador, del maestro. Armado de voluntariedad, de dedicación, de entusiasmo, de imaginación o de humanidad. Atareado en su labor de recomponer las vidas de niños o jóvenes, víctimas involuntarias de la exclusión, la precariedad y la violencia. Ya sean párvulos en Hong Kong, adolescentes en un instituto de Long Beach, "intocables" en un centro de Katmandú o delincuentes en un reformatorio de Roma.

\footnotetext{
${ }^{27}$ Podríamos traer a la memoria películas como El chico (1921) de Charles Chaplin, En el nombre del padre (1993) de Jim Sheridan o más recientemente Evelyn (2003) de Bruce Beresford.
} 


\section{REFERENCIAS}

AMBRÒS, Alba; BREU, Ramón. El cine en la escuela. Barcelona, Graó, 2011, 200 p.

AUMONT, Jacques et al. Estética del cine. Barcelona, Paidós, 1995, 282 p.

FILMAFFINITY. Disponible en: <http://www.filmaffinity.com/es/main.html>. Consulta el: 16 de marzo de 2017.

GRUWELL, Erin. EI diario de los escritores de la libertad. Barcelona, Elipsis Ediciones, 2007,378 p.

GUICHOT REINA, Virginia. El cine como reflejo del imaginario social: una aproximación al estudio de la representación de la educación escolar en la Historia de la educación en España desde la II República hasta el final del régimen franquista. In: DÁVILA, Paulí; NAYA, Luis $\mathrm{M}^{\mathrm{a}}$ (Coords). Espacios y Patrimonio histórico-educativo. Donosti, Universidad del País Vasco, 2016, 1372 p.

HUERVA SUBIRACHS, Joan. Hong Kong. Crisis en el modelo 'un país dos sistemas'. Anuari del conflicte social, Barcelona, p. 229-245, 2014.

KASHUA, Sayed. Arabes danzantes. Salamanca, Tropismos, 2006, 242 p.

LOSCERTALES ABRIL, Felicidad. Violencia en las aulas. La visión del cine como espejo social. Revista Interuniversitaria de Formación del Profesorado, 41, p. 115-132, 2001.

. El conflicto de enseñar cuando se es mujer. In: LOSCERTALES ABRIL, Felicidad (Cood.). Profesoras de película. Las mujeres docentes vistas por el cine. Sevilla: Ediciones Alfar, 2016, 280 p.

MARTÍNEZ-SALANOVA SÁNCHEZ, Enrique. El valor del cine para aprender y enseñar. Comunicar. Revista Científica de Comunicación y Educación, Huelva, 20, p. -52, 2003.

- El valor de la imagen en movimiento. Comunicar. Revista Científica de Comunicación y Educación, Huelva, 9, p. 23-35, 1997.

REPÚBLICA Democrática del Congo: pagar para aprender. El clientelismo escolar. Disponible en: $\quad<$ http://www.jrs.net/assets/regions/ior/media/files/kisanganiedues.pdf $>$. Consulta el: 16 de marzo de 2017.

SUBIRANA, Victoria. Una Maestra en Katmandú. Madrid, Aguilar, 2012, 368 p.

STANLEYVILLE. Disponible en: <http://www.stanleyville.be/athenee.html\#>. Consulta el: 16 de marzo de 2017.

ZAPLANA MARÍN, Andrés. Entre pizarras y pantallas: profesores en el cine. Badajoz, Diputación de Badajoz, 2005, 647 p. 